\title{
Vanillin improves scopolamine-induced memory impairment through restoration of ID1 expression in the mouse hippocampus
}

\author{
JAE-CHUL LEE $^{1 *}$, IN HYE KIM ${ }^{1 *}$, JEONG HWI CHO ${ }^{1}$, TAE-KYEONG LEE ${ }^{1}$, \\ JOON HA PARK ${ }^{2}$, JI HYEON AHN ${ }^{2}$, BICH NA SHIN ${ }^{3}$, BING CHUN YAN ${ }^{4}$, JONG-DAI KIM ${ }^{5}$, \\ YONG HWAN JEON ${ }^{6}$, YOUNG JOO LEE ${ }^{7}$, MOO-HO WON $^{1}$ and IL JUN KANG ${ }^{8}$
}

\begin{abstract}
${ }^{1}$ Department of Neurobiology, School of Medicine, Kangwon National University, Chuncheon, Gangwon 24341; ${ }^{2}$ Department of Biomedical Science, Research Institute of Bioscience and Biotechnology; ${ }^{3}$ Department of Physiology, College of Medicine, Hallym University, Chuncheon, Gangwon 24252, Republic of Korea; ${ }^{4}$ Institute of Integrative Traditional and Western Medicine, Medical College, Yangzhou University, Yangzhou, Jiangsu 225001, P.R. China; ${ }^{5}$ Division of Food Biotechnology, School of Biotechnology, Kangwon National University, Chuncheon, Gangwon 24341;

${ }^{6}$ Department of Radiology, School of Medicine, Kangwon National University, Chuncheon, Gangwon 24289; ${ }^{7}$ Department of Emergency Medicine, Seoul Hospital, College of Medicine, Sooncheonhyang University, Seoul 04401; ${ }^{8}$ Department of Food Science and Nutrition, Hallym University, Chuncheon, Gangwon 24252, Republic of Korea
\end{abstract}

Received July 14, 2017; Accepted September 26, 2017

DOI: $10.3892 / \mathrm{mmr} .2018 .8401$

\begin{abstract}
Hydroxy-3-methoxybenzaldehyde (vanillin), contained in a number of species of plant, has been reported to display beneficial effects against brain injuries. In the present study, the impact of vanillin on scopolamine-induced alterations in cognition and the expression of DNA binding protein inhibitor ID-1 (ID1), one of the inhibitors of DNA binding/differentiation proteins that regulate gene transcription, in the mouse hippocampus. Mice were treated with $1 \mathrm{mg} / \mathrm{kg}$ scopolamine with or without $40 \mathrm{mg} / \mathrm{kg}$ vanillin once daily for 4 weeks. Scopolamine-induced cognitive impairment was observed from 1 week and was deemed to be severe 4 weeks following the administration of scopolamine. However, treatment with vanillin in scopolamine-treated mice markedly attenuated cognitive impairment 4 weeks following treatment with scopolamine. ID1-immunoreactive cells were
\end{abstract}

Correspondence to: Professor Moo-Ho Won, Department of Neurobiology, School of Medicine, Kangwon National University, 1 Gangwondaehak-gil, Chuncheon, Gangwon 24341, Republic of Korea

E-mail: mhwon@kangwon.ac.kr

Professor Il Jun Kang, Department of Food Science and Nutrition, Hallym University, 1 Hallimdaehak-gil, Chuncheon, Gangwon 24252, Republic of Korea

E-mail: ijkang@hallym.ac.kr

${ }^{*}$ Contributed equally

Key words: muscarinic acetylcholine receptor, cholinergic transmission, cognitive deficits, DNA binding protein inhibitor, 4-hydroxy-3-methoxybenzaldehyde revealed in the hippocampus of vehicle-treated mice, and were hardly detected 4 weeks following treatment with scopolamine. However, treatment with vanillin in scopolamine-treated mice markedly restored ID1-immunoreactive cells and expression 4 weeks subsequent to treatment. The results of the present study suggested that vanillin may be beneficial for cognitive impairment, by preventing the reduction of ID1 expression which may be associated with cognitive impairment.

\section{Introduction}

The hippocampus is an important component of the limbic system and serves a role in regulating emotionality and cognitive processes, including memory consolidation, learning, and information retrieval (1-4). The loss of cholinergic function in the hippocampus is correlated with marked cognitive impairment $(5,6)$.

Scopolamine, a muscarinic acetylcholine receptor antagonist, interferes with cholinergic transmission in the brain (7). It has been reported that scopolamine may impair memory performance in humans and animals (8) and that scopolamine may induce dysregulation of cholinergic activity in the hippocampus, leading to impairments in learning and memory $(9,10)$. Therefore, scopolamine has been used for the induction of learning and memory impairment in experimental animals (11-13).

4-Hydroxy-3-methoxybenzaldehyde (vanillin) is a phenolic constituent synthesized by various types of plants, including Gastrodia elata Blume (Orchidaceae) $(14,15)$. Previous studies have suggested that vanillin has a variety of beneficial effects against brain injuries via a number of therapeutic properties, including anti-inflammatory, antioxidant and anti-cancer activities (16-19). For example, vanillin administered following cerebral ischemia prevented neuronal damage/death in the CA1 area of the hippocampus in gerbils (20). However, few studies 
regarding effects of vanillin against scopolamine-induced cognitive impairment have been reported.

DNA binding protein inhibitor (ID) proteins control gene transcription via inhibitory binding to basic helix-loop-helix (bHLH) transcription factors, and four members of this protein family (ID1, 2, 3 and 4) have been identified in mammals (21-24). Members of the ID protein family share a highly conserved bHLH domain and are similar in size (13-20 kDa); however, these proteins display extensive sequence variation outside the bHLH domain (25). ID proteins, as transcription factors, serve roles in cell cycle regulation and apoptosis, the development of the nervous system, muscle development and tumorigenesis $(24,26,27)$. It has been reported that ID1-imunoreactive cells are $\gamma$-aminobutyric acid (GABA) ergic interneurons in the gerbil hippocampus (28), and that GABAergic neuronal dysfunction is responsible for network alteration associated with cognitive deficits in Alzheimer's disease and aging (29-31). To the best of our knowledge, however, few studies regarding alterations in ID1 expression in animal models of scopolamine-induced cognitive deficits have been reported. Therefore, the present study examined the long-term effects of treatment with vanillin on scopolamine-induced cognitive impairment and alterations in ID1 expression in the mouse hippocampus.

\section{Materials and methods}

Experimental animals. A total of 210 male ICR mice (25-30 g body weight; 8 weeks of age) were used, and were handled according to the guidelines of the current international laws and policies (Guide for the Care and Use of Laboratory Animals, The National Academies Press, 8th Ed., 2011). The present study was approved based on ethical procedures and scientific care by the Kangwon National University Institutional Animal Care and Use Committee (approval no. KW-130424-2). The mice were maintained under a $12 \mathrm{~h}$ light/dark cycle at $23^{\circ} \mathrm{C}$ and $60 \%$ humidity with free access to food and water.

Animals ( $n=70 /$ group) were intraperitoneally injected with $1 \mathrm{mg} / \mathrm{kg}$ scopolamine (Sigma-Aldrich; Merck KGaA, Darmstadt, Germany) once daily for 4 weeks. The scopolamine dose was selected based on previously published studies $(32,33)$. Scopolamine-treated animals were simultaneously administered $40 \mathrm{mg} / \mathrm{kg}$ vanillin (Sigma-Aldrich; Merck KGaA), which was suspended in $1 \mathrm{ml} 10 \%$ Tween-80 solution. The vanillin dose was selected based on a previous study (20) and was orally administered using a feeding needle once daily for 4 weeks. Vehicle -treated control mice were treated with the same volume of saline. Mice were sacrificed at 1,2, 3 and 4 weeks following treatment with saline or scopolamine + vanillin ( $\mathrm{n}=14$ at each time point). The mice were weighed twice per week; no significant differences were observed in body weight between all the groups (data not shown).

Passive avoidance test. Short-term memory capacity was determined by assessing the latency in a passive avoidance test, according to the method of Horisawa et al (34). The test was performed with an apparatus consisting of light and dark compartments with a grid floor (GEM 392; San Diego Instruments, Inc., San Diego, CA, USA). In the training session, mice were permitted to explore the environments of the two compartments for $1 \mathrm{~min}$, and the mice were administered an inescapable foot shock $(0.3 \mathrm{~mA}$ for $3 \mathrm{sec})$ upon entering the dark compartment. The test session was performed $15 \mathrm{~min}$ subsequent to the training session, without applying the foot shock. The latency time of the passive avoidance test was defined as the difference between the start of the test session and the entry of the mouse into the dark compartment. Latency was recorded as $180 \mathrm{sec}$ when the mouse did not enter the dark compartment within $180 \mathrm{sec}$.

Water maze performance. Spatial learning and memory were tested using the Morris water maze task, using the procedure of Wang et al (35). A circular pool of $90 \mathrm{~cm}$ in diameter and $45 \mathrm{~cm}$ in height was filled with water and divided into 4 sectors. A platform of $6 \mathrm{~cm}$ in diameter and $29 \mathrm{~cm}$ in height was placed in one sector, $1 \mathrm{~cm}$ below the surface of the water. Training was performed for 3 consecutive days prior to the test. The test was performed on the last day of each week. Mice were permitted to swim for $120 \mathrm{sec}$ to search for the hidden platform. At the end of each trial, each mouse remained on the platform for $3 \mathrm{sec}$. The escape latency, the time taken to find the platform, was recorded using the Noldus Ethovision video tracking system (Ethovision XT; Noldus Information Technology B.V., Wageningen, The Netherlands).

Western blot analysis. ID1 levels in the mouse hippocampus ( $n=7$ at each time point) were analyzed using a previously-published method (28). Hippocampal tissues were homogenized and ID1 levels were determined using a micro bicinchoninic acid (BCA) protein assay kit (Pierce; Thermo Fisher Scientific, Inc., Waltham, MA, USA). Nitrocellulose transfer membranes (Pall Life Sciences, Port Washington, NY, USA) were incubated with rabbit anti-ID1 (1:1,000; sc-488; Santa Cruz Biotechnology, Inc., Dallas, TX, USA), $\beta$-actin (1:2,000, sc-47778; Santa Cruz Biotechnology, Inc.) and exposed to peroxidase-conjugated goat anti-rabbit immunoglobulin G (1:2,000; sc-2004; Santa Cruz Biotechnology, Inc.) for $2 \mathrm{~h}$ at $4^{\circ} \mathrm{C}$ and an enhanced luminol-based chemiluminescence kit (Pierce; Thermo Fisher Scientific, Inc.). The results of this analysis were scanned and densitometric analysis, as the relative optical density (ROD), was used for quantification of the bands using Scion Image software, version 2.0 (Scion Corporation, Frederick, MD, USA). A ratio of the ROD was calibrated as a percentage, with control mice designated as $100 \%$.

Tissue processing for histology. In short, as previously described (30), mice were anaesthetized $(n=7$ at each time point) with sodium pentobarbital $(30 \mathrm{mg} / \mathrm{kg}$; intraperitoneal injection) and tissues were fixed with $4 \%$ paraformaldehyde for $6 \mathrm{~h}$ at $4^{\circ} \mathrm{C}$. The brains were serially sectioned into $30-\mu \mathrm{m}$ coronal sections using a cryostat (Leica Microsystem $\mathrm{GmbH}$, Wetzlar, Germany).

Fluoro-Jade B(F-J B) histofluorescence. In order to observe the localization of neuronal degeneration, F-J B histofluorescence staining was performed, according to a previously-published procedure (36). The sections were immersed in a $0.06 \%$ potassium permanganate solution and stained with $0.0004 \%$ F-J B 
(Histo-Chem, Inc., Jefferson, AR, USA) staining solution. The stained tissues were analyzed using an epifluorescent microscope (magnification, x200; Zeiss AG, Oberkochen, Germany) with blue (450-490 $\mathrm{nm}$ ) excitation light and a barrier filter.

Immunohistochemistry. Immunohistochemistry for NeuN (a neuronal marker) and ID1 was performed using a published procedure (28). The sections were incubated in mouse anti-NeuN (1:800; MAB377; EMD Millipore, Billerica, MA, USA) or rabbit anti-ID1 (1:200; sc-488; Santa Cruz Biotechnology, Inc.) as primary antibodies, and in biotinylated horse anti-mouse (1:200; BA-2001; Vector Laboratories, Inc., Burlingame, CA, USA or rabbit anti-goat immunoglobulin G (1:200; BA-1100; Vector Laboratories, Inc.) and streptavidin peroxidase complex (VECTASTAIN ${ }^{\circledR}$ Elite ABC kit 1:200; Vector Laboratories, Inc.) as secondary antibodies. The antibodies were finally visualized with 3,3'-diaminobenzidine tetrahydrochloride. A negative control test was performed to establish the specificity of the immunostaining using pre-blocking serum (S-1000; Vector Laboratories, Inc.) instead of primary antibody. The negative control test showed no immunoreactivity in structures observed.

Data analysis. As previously described (37), the numbers of NeuN-immunoreactive and F-J B-positive cells were counted. A total of 10 sections per mouse were selected according to anatomical landmarks $(-1.4$ to $-2.2 \mathrm{~mm}$ from anterior to posterior) of the gerbil brain atlas. Cells were counted in a $200 \times 200-\mu \mathrm{m}$ square at the center of the stratum pyramidale of the CA1-3 and dentate gyrus by averaging total cell numbers from each mouse per group. A ratio of the count was calibrated as a percentage of the sham group ( $\mathrm{NeuN}$-immunoreactive cells) or ischemia group (F-J B-positive cells).

Quantitative analysis of ID1 immunoreactivity was performed as previously described (37). In short, seven sections per animal were selected. Digital images of ID1-immunoreactive structures were captured with an AxioM1 light microscope (Zeiss AG) equipped with a digital camera (Axiocam; Zeiss AG) connected to a PC monitor, and the density of the structures was evaluated based on optical density (OD), which was obtained following the transformation of the mean gray level using the formula: $O D=\log$ (256/mean gray level). Background density in the images was subtracted, and brightness and contrast were calibrated as a percentage (ROD) using Adobe Photoshop version 8.0 (Adobe Systems, Inc., San Jose, CA, USA) and analyzed using ImageJ software, version 1.59 (National Institutes of Health, Bethesda, MD, USA). A ratio of the ROD was calibrated as a percentage, with control mice designated as $100 \%$.

Statistical analysis. Data are expressed as the mean \pm standard error of the mean. The test of normality was performed using the Kolmogorov and Smirnov test for assessing normal distributions, and the Bartlett test for assessing identical standard distributions. All data passed the normality test. A multiple-sample comparison was applied to test the differences between groups (analysis of variance and the Tukey multiple range test as post hoc test using the criterion of the least significant differences). Statistical analysis was performed using GraphPad Prism, version 4.0 (GraphPad Software, Inc., La Jolla, CA, USA). P<0.05 was considered to indicate a statistically significant difference.

\section{Results}

Passive avoidance test. The passive avoidance test was performed to examine the protective effect of vanillin against scopolamine-induced learning and memory defects (Fig. 1A). No significant difference was observed in the latency time over the 4 weeks in the vehicle-treated mice. However, a reduction in the latency time was observed in the scopolamine-treated mice; the latency time was significantly decreased at 1 week post-treatment with scopolamine, and the decreased latency time was maintained until 4 weeks (Fig. 1A). Cotreatment with scopolamine and vanillin improved the reduction of the latency time from 2 weeks following the cotreatment, and the decreased latency times was significantly recovered 4 weeks subsequent to the cotreatment (Fig. 1A).

Morris water maze test. The Morris water maze test was performed to investigate the effect of vanillin against scopolamine-induced spatial memory impairment. As presented in Fig. 1B, the vehicle-treated mice readily learned and memorized the position of the submerged hidden platform, and exhibited significantly decreased escape latency at 4 weeks post-training. However, in the scopolamine-treated mice, the escape latency was significantly longer compared with the vehicle-treated mice at 1 week following treatment with scopolamine, and the increased escape latency was maintained until 4 weeks (Fig. 1B). Cotreatment with scopolamine and vanillin improved the escape latency from 2 weeks following the cotreatment, and significantly recovered the escape latency at 4 weeks subsequent to the cotreatment (Fig. 1B).

ID-1 protein levels. According to the results of the western blot analysis, the level of ID-1 protein in the scopolamine-treated mice gradually decreased from 1 week following treatment with scopolamine compared with the vehicle-treated mice, and was significantly decreased at 2 and 4 weeks post-treatment with scopolamine (Fig. 2). However, cotreatment with scopolamine and vanillin increased the ID-1 protein level to a level consistent with that in the vehicle-treated mice at 4 weeks subsequent to the cotreatment (Fig. 2).

Neuronal damage. Neuronal damage following treatment with scopolamine was examined in the hippocampus via NeuN immunohistochemistry and F-J B histofluorescence staining (data not shown). NeuN-immunoreactive cells were observed in the pyramidal layer of the hippocampus (CA1-3 areas) and in the granule cell layer of the dentate gyrus of the vehicle-treated mice. The morphology of NeuN-immunoreactive cells in the scopolamine-treated mice was consistent with that in the vehicle-treated mice. In addition, F-J B-positive cells, which are damaged cells, were not observed in any regions of the scopolamine-treated mice. This result was consistent with the results of previous studies $(10,33)$. These findings indicated that treatment with scopolamine did not evoke neuronal death in the hippocampus. 

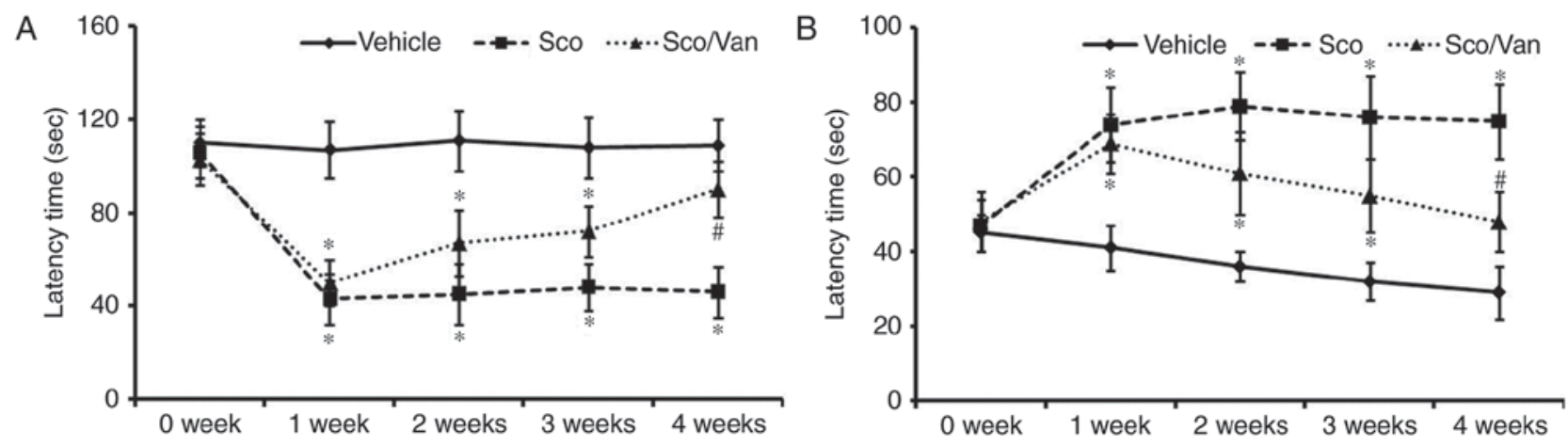

Figure 1. Effects of vanillin against the scopolamine-induced alteration of cognitive defects. (A) Passive avoidance test. (B) Morris water maze test. $\mathrm{n}=14$ mice/group. " $\mathrm{P}<0.05$ vs. vehicle; ${ }^{\prime} \mathrm{P}<0.05$ vs. Sco. Error bars indicate the mean \pm standard error of the mean. Sco, scopolamine-treated; Sco/Van, scopolamine/vanillin-cotreated.

\section{ID-1 immunoreactivity}

CA1 area. ID-1 immunohistochemistry results are presented in Fig. 3. ID-1-immunoreactive cells were distributed in all layers of the CA1 area in the vehicle-treated mice (Fig. 3A). In the scopolamine-treated mice, ID-1 immunoreactivity was gradually decreased from 1 week following treatment with scopolamine, and ID-1 immunoreactivity was markedly decreased at 4 weeks post-treatment with scopolamine (Fig. 3B-D). However, the distribution pattern of ID-1-immunoreactive structures in the scopolamine and vanillin-cotreated mice was similar to that in the vehicle-treated mice (Fig. 3E). In addition, the ROD of ID-1 immunoreactivity in the hippocampal areas are presented in Fig. 3P-R.

CA2/3 area. The pattern of ID-1-immunoreactive structures in the CA2/3 area following treatment with scopolamine was broadly similar to the alteration in ID-1-immunoreactivity in the CA1 area (Fig. 3F-I). Cotreatment with scopolamine and vanillin generated results similar to those in the CA1 area (Fig. 3J).

Dentate gyrus. ID-1-immunoreactive cells were primarily distributed in the polymorphic layer in the vehicle-treated mice (Fig. 3K). At 1 week post-treatment with scopolamine, ID-1 immunoreactive cells and immunoreactivity were markedly decreased (Fig. 3L). Thereafter, ID-1 immunoreactivity was gradually decreased following scopolamine treatment (Fig. 3M and N). However, ID-1-immunoreactivity in the co-treated mice was similar to that in the vehicle-treated mice at 4 weeks post-cotreatment (Fig. 3O).

\section{Discussion}

The passive avoidance test is a measurement of learning and memory based on avoidance of a fear-inducing stimulus. In the passive avoidance test, rodents naturally prefer dark compartments; however, receiving an electric shock in the dark compartment causes a conflict to this tendency (38). The Morris water maze test is performed to assess spatial memory in rodents $(39,40)$. In the present study, chronic systemic treatment with scopolamine induced an impairment in learning and memory, and spatial memory, in mice from 1 week post-treatment, and the impairment deteriorated over time, as
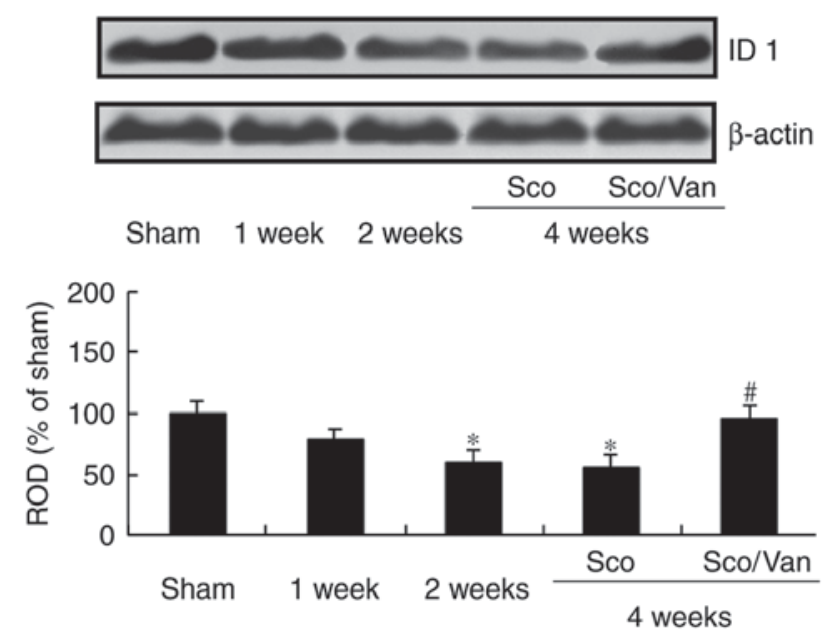

Figure 2. Western blot analysis of ID1 in the hippocampus. Cotreatment with scopolamine and vanillin restored the ID1 level at 4 weeks following cotreatment. ROD as percentage values of the immunoblot band is presented. $\mathrm{n}=7$ mice/group. ${ }^{*} \mathrm{P}<0.05$ vs. vehicle; ${ }^{\text {}} \mathrm{P}<0.05$ vs. Sco at 4 weeks. Error bars indicate the mean \pm standard error of the mean. Sco, scopolamine-treated; Sco/Van, scopolamine/vanillin-cotreated; ID1, DNA binding protein inhibitor ID-1; ROD, relative optical density.

observed in the passive avoidance and water maze tests. Based on the above previous reports and the results of the present study, chronic systemic treatment with scopolamine may be a viable method for developing cognitive impairment in rodents.

The results of the present study demonstrated that no neuronal loss was present in the mouse hippocampus following treatment with scopolamine for 4 weeks via NeuN immunohistochemistry and F-J B histofluorescence, proven histological methods for the examination of neuronal death or loss in the brain. Recently, it was reported that chronic treatment with scopolamine induced a significant reduction in neurogenesis of the hippocampal dentate gyrus in mice, closely associated with hippocampus-dependent learning and memory, without loss of neurons in the mouse dentate gyrus (33). This previous result indicated that chronic systemic treatment with scopolamine may induce cognitive deficits without neuronal loss in the mouse hippocampus.

The present study evaluated the effects of vanillin on scopolamine-induced cognitive impairment using passive avoidance and the Morris water maze tests in mice, and 


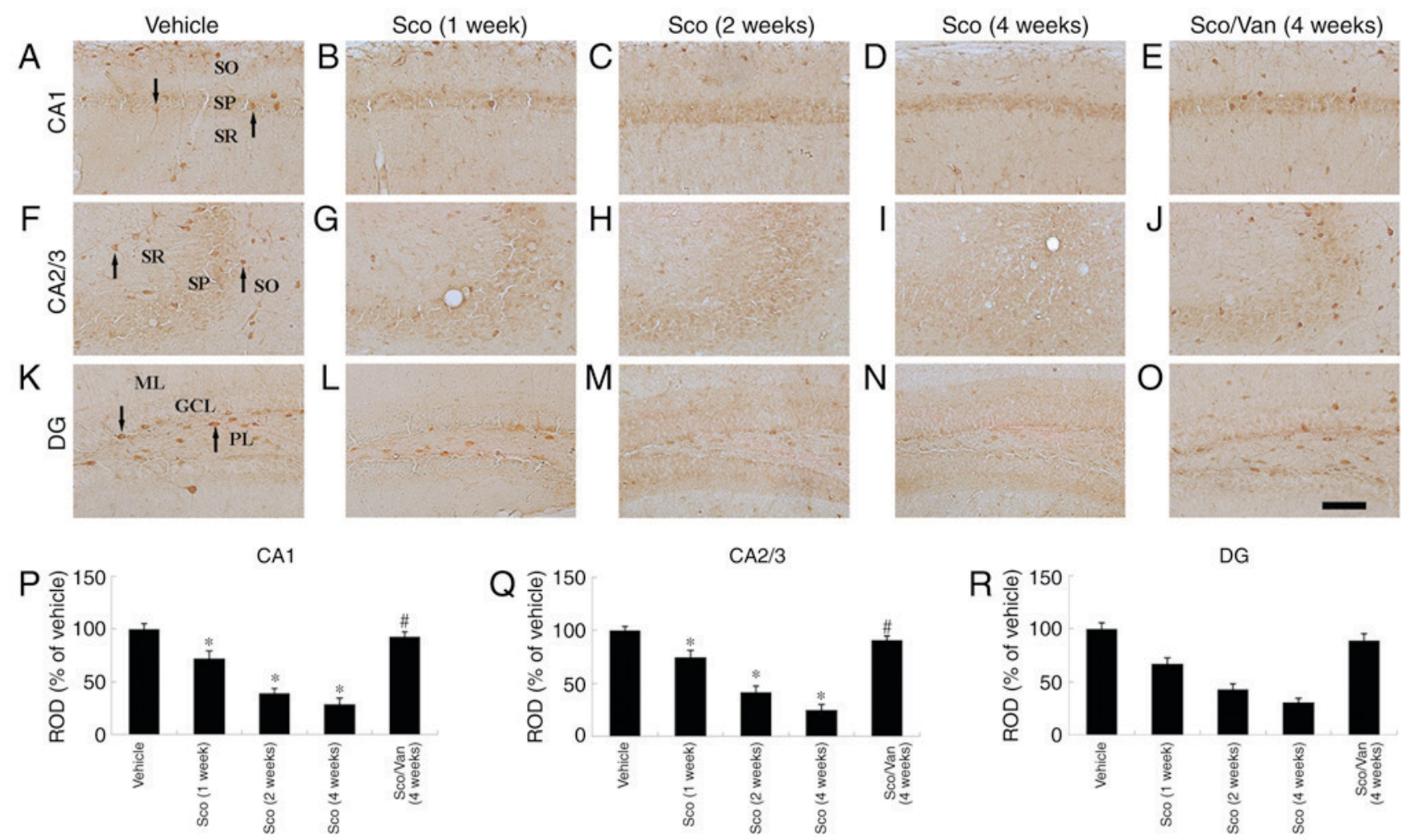

Figure 3. ID1 immunohistochemistry in the CA1, CA2/3 and dentate gyrus (DG) regions of the vehicle-treated (A, F, K), scopolamine-treated (B-D, G-I, L-N), and scopolamine/vanillin-treated mice (E, J, O). ID1-immunoreactive cells (arrows) in the vehicle-treated mice were observed in CA1-3 and the dentate gyrus. In the scopolamine-treated mice, ID1-immunoreactive cells were markedly decreased from 1 week post-treatment with scopolamine. In the cotreated mice, ID1-immunoreactive cells were markedly increased compared with the vehicle-treated mice. Scale bar, $100 \mu \mathrm{m}$. (P, Q and R) ROD as percentage values of ID1 immunoreactivity in the mouse hippocampus. $\mathrm{n}=7$ mice/group. ${ }^{*} \mathrm{P}<0.05$ vs. vehicle; ${ }^{*} \mathrm{P}<0.05$ vs. Sco at 4 weeks. Error bars indicate the mean \pm standard error of the mean. GCL, granule cell layer; ML, molecular layer; PL, polymorphic layer; SO, stratum oriens; SP, stratum pyramidale; SR, stratum radiatum; Sco, scopolamine-treated; Sco/Van, scopolamine/vanillin-cotreated; ID1, DNA binding protein inhibitor ID-1; ROD, relative optical density.

revealed that treatment with vanillin significantly attenuated cognitive impairment induced by scopolamine. Vanillin has been demonstrated to display multifunctional effects, including anti-inflammatory, antioxidant and anti-cancer effects (16-19). Recently, Gupta and Sharma (41) demonstrated that vanillin markedly attenuated learning and memory deficits in a rat model of Huntington's disease induced by 3 -nitropropionic acid. It is known that scopolamine causes cognitive impairments by decreasing central cholinergic activity in experimental animals (42-44). In addition, Shi et al (45) reported that long-term scopolamine injections led to cognitive deficits, closely associated with cyclic-AMP responsive element-binding protein signaling activity in the cerebral cortex and dorsal hippocampus in rats.

Recently, it was reported that vanillin and 4-hydroxybenzyl alcohol effectively attenuated learning and memory impairment, and the reduction of cell proliferation and neuroblast differentiation, in the mouse hippocampal dentate gyrus following treatment with scopolamine (46). This previous result indicated that vanillin may reverse the scopolamine-induced decrease in cell proliferation and neuroblast differentiation in the hippocampal dentate gyrus. In this regard, adult neurogenesis in the hippocampus is implicated in learning and memory processes (47). ID proteins are included in a number of physiological and pathological processes, including cell growth, differentiation, senescence and survival $(24,26,27)$. In particular, ID proteins serve important roles in adult neurogenesis through the regulation of quiescence and self-renewal of neural stem cells, in addition to neuronal differentiation (48-51). For example, ID1 exhibits precocious neurogenesis by sustaining transcription factor HES-1 expression in the mouse brain (52). To the best of our knowledge, no studies regarding the association between ID proteins and scopolamine-induced cognitive deficits have been reported, and the alteration of ID expression in the hippocampus with cognitive impairment has not investigated. The present study examined whether vanillin may improve scopolamine-induced cognitive impairment by preventing the reduction of immunoreactivity and the expression of ID1 protein in the mouse hippocampus, and it was observed that the ID1 protein level in the hippocampus was decreased from 1 week and was significantly decreased at 4 weeks post-treatment with scopolamine. In addition, ID1 immunoreactivity in cells in the hippocampal CA1-3 areas and dentate gyrus significantly decreased from 1 week and disappeared 4 weeks post-treatment with scopolamine. Therefore, it is likely that a decrease in or inhibition of ID1 expression in hippocampal neurons following chronic systemic treatment with scopolamine may be associated with scopolamine-induced cognitive deficits, and that treatment with vanillin in scopolamine-treated mice significantly restored ID1-immunoreactive cells and expression 4 weeks subsequent to the treatment.

GABAergic interneurons synthesize and release GABA, and contribute substantially to inhibitory regulation in the 
adult neuronal network (53). It was previously demonstrated that cognitive deficiency is caused by the degeneration of GABAergic neurons in the medial septal region $(54,55)$. Studies have reported that GABAergic neuronal dysfunction is responsible for the network alteration associated with cognitive deficits in Alzheimer's disease and aging (29-31). In addition, GABAergic neurons express the muscarinic acetylcholine receptor (56), and scopolamine blocks muscarinic receptors in GABAergic neurons. Studies have suggested that the muscarinic acetylcholine receptor may mediate the antidepressant action of scopolamine $(57,58)$. According to these previous results, it may be suggested that GABAergic-cholinergic interactions in the hippocampus may affect cognitive deficits. Li et al (59) reported that GABAergic interneuronal dysfunction may lead to an impairment in adult hippocampal neurogenesis in mice. In addition, a recent study reported that ID1-immunoreactive cells were identified as GABAergic interneurons (28). In the present study, ID1 immunoreactivity, which is expressed in GABAergic interneurons in the mouse hippocampus, was readily inhibited by chronic treatment with scopolamine. Based on the above findings, it may be suggested that the ID1 protein is involved in the dysfunction of GABAergic neurons following treatment with scopolamine.

In conclusion, the results of the present study revealed that vanillin was able to significantly improve scopolamine-induced cognitive impairment by preventing the reduction of immunoreactivity and expression of ID1 protein in the mouse hippocampus. Therefore, vanillin may be efficacious for the prevention and treatment of cognitive impairment and is a worthy candidate for clinical evaluation.

\section{Acknowledgements}

The present study was supported by the Bio-Synergy Research Project (grant no. NRF-2015M3A9C4076322) of the Ministry of Science, ICT and Future Planning through the National Research Foundation and the Basic Science Research Program through the National Research Foundation of Korea funded by the Ministry of Science, ICT \& Future Planning (grant no. 2017R1A2B4008403).

\section{References}

1. Hami J, Kheradmand H and Haghir H: Sex differences and laterality of insulin receptor distribution in developing rat hippocampus: An immunohistochemical study. J Mol Neurosci 54: 100-108, 2014.

2. Huang W, Cao J, Liu X, Meng F, Li M, Chen B and Zhang J: AMPK Plays a dual role in regulation of CREB/BDNF pathway in mouse primary hippocampal cells. J Mol Neurosci 56 : 782-788, 2015.

3. Kong Y, Bai PS, Sun H and Nan KJ: Expression of the newly identified gene $\mathrm{CAC} 1$ in the hippocampus of Alzheimer's disease patients. J Mol Neurosci 47: 207-218, 2012.

4. Zhao L, Sun C, Xiong L, Yang Y, Gao Y, Wang L, Zuo H, Xu X, Dong J, Zhou H and Peng R: MicroRNAs: Novel mechanism involved in the pathogenesis of microwave exposure on Rats Hippocampus. J Mol Neurosci 53: 222-230, 2014.

5. Lippa AS, Critchett DJ, Ehlert F, Yamamura HI, Enna SJ and Bartus RT: Age-related alterations in neurotransmitter receptors: An electrophysiological and biochemical analysis. Neurobiol Aging 2: 3-8, 1981.

6. Vijayan VK: Cholinergic enzymes in the cerebellum and the hippocampus of the senescent mouse. Exp Gerontol 12: 7-11, 1977.
7. Bartus RT, Dean RL III, Beer B and Lippa AS: The cholinergic hypothesis of geriatric memory dysfunction. Science 217 : 408-414, 1982.

8. Grasby PM, Frith CD, Paulesu E, Friston KJ, Frackowiak RS and Dolan RJ: The effect of the muscarinic antagonist scopolamine on regional cerebral blood flow during the performance of a memory task. Exp Brain Res 104: 337-348, 1995.

9. Lee B, Sur B, Shim J, Hahm DH and Lee H: Acupuncture stimulation improves scopolamine-induced cognitive impairment via activation of cholinergic system and regulation of BDNF and CREB expressions in rats. BMC Complement Altern Med 14: 338, 2014.

10. Yoo DY, Choi JH, Kim W, Nam SM, Jung HY, Kim JH, Won MH, Yoon YS and Hwang IK: Effects of luteolin on spatial memory, cell proliferation, and neuroblast differentiation in the hippocampal dentate gyrus in a scopolamine-induced amnesia model. Neurol Res 35: 813-820, 2013.

11. Ebert U and Kirch W: Scopolamine model of dementia: Electroencephalogram findings and cognitive performance. Eur J Clin Invest 28: 944-949, 1998.

12. Klinkenberg I and Blokland A: The validity of scopolamine as a pharmacological model for cognitive impairment: A review of animal behavioral studies. Neurosci Biobehav Rev 34: 1307-1350, 2010.

13. Xu H, You Z, Wu Z, Zhou L, Shen J and Gu Z: WY14643 attenuates the scopolamine-induced memory impairments in mice. Neurochem Res 41: 2868-2879, 2016.

14. Jung JW, Yoon BH, Oh HR, Ahn JH, Kim SY, Park SY and Ryu JH: Anxiolytic-like effects of Gastrodia elata and its phenolic constituents in mice. Biol Pharm Bull 29: 261-265, 2006.

15. Lee YS, Ha JH, Yong CS, Lee DU, Huh K, Kang YS, Lee SH, Jung MW and Kim JA: Inhibitory effects of constituents of Gastrodia elata Bl. On glutamate-induced apoptosis in IMR-32 human neuroblastoma cells. Arch Pharm Res 22: 404-409, 1999.

16. Lirdprapamongkol K, Sakurai H, Kawasaki N, Choo MK, Saitoh Y, Aozuka Y, Singhirunnusorn P, Ruchirawat S, Svasti J and Saiki I: Vanillin suppresses in vitro invasion and in vivo metastasis of mouse breast cancer cells. Eur J Pharm Sci 25: 57-65, 2005.

17. Murakami Y, Hirata A, Ito S, Shoji M, Tanaka S, Yasui T, Machino $M$ and Fujisawa S: Re-evaluation of cyclooxygenase-2-inhibiting activity of vanillin and guaiacol in macrophages stimulated with lipopolysaccharide. Anticancer Res 27: 801-807, 2007.

18. Wu SL, Chen JC, Li CC, Lo HY, Ho TY and Hsiang CY: Vanillin improves and prevents trinitrobenzene sulfonic acid-induced colitis in mice. J Pharmacol Exp Ther 330: 370-376, 2009.

19. Tai A, Sawano T, Yazama F and Ito H: Evaluation of antioxidant activity of vanillin by using multiple antioxidant assays. Biochim Biophys Acta 1810: 170-177, 2011.

20. Kim HJ, Hwang IK and Won MH: Vanillin, 4-hydroxybenzyl aldehyde and 4-hydroxybenzyl alcohol prevent hippocampal CA1 cell death following global ischemia. Brain Res 1181: 130-141, 2007.

21. Kee Y and Bronner-Fraser M: To proliferate or to die: Role of Id3 in cell cycle progression and survival of neural crest progenitors. Genes Dev 19: 744-755, 2005.

22. Massari ME and Murre C: Helix-loop-helix proteins: Regulators of transcription in eucaryotic organisms. Mol Cell Biol 20: 429-440, 2000

23. Perk J, Iavarone A and Benezra R: Id family of helix-loop-helix proteins in cancer. Nat Rev Cancer 5: 603-614, 2005.

24. Ruzinova MB and Benezra R: Id proteins in development, cell cycle and cancer. Trends Cell Biol 13: 410-418, 2003.

25. Nair R, Teo WS, Mittal V and Swarbrick A: ID proteins regulate diverse aspects of cancer progression and provide novel therapeutic opportunities. Mol Ther 22: 1407-1415, 2014.

26. Lasorella A, Benezra R and Iavarone A: The ID proteins: Master regulators of cancer stem cells and tumour aggressiveness. Nat Rev Cancer 14: 77-91, 2014

27. Ling F, Kang B and Sun XH: Id proteins: Small molecules, mighty regulators. Curr Top Dev Biol 110: 189-216, 2014.

28. Lee JC, Chen BH, Cho JH, Kim IH, Ahn JH, Park JH, Tae HJ, Cho GS, Yan BC, Kim DW, et al: Changes in the expression of DNA-binding/differentiation protein inhibitors in neurons and glial cells of the gerbil hippocampus following transient global cerebral ischemia. Mol Med Rep 11: 2477-2485, 2015.

29. Andrews-Zwilling Y, Gillespie AK, Kravitz AV, Nelson AB, Devidze N, Lo I, Yoon SY, Bien-Ly N, Ring K, Zwilling D, et al: Hilar GABAergic interneuron activity controls spatial learning and memory retrieval. PLoS One 7: e40555, 2012. 
30. McQuail JA, Frazier CJ and Bizon JL: Molecular aspects of age-related cognitive decline: The role of GABA signaling. Trends Mol Med 21: 450-460, 2015.

31. Palop JJ, Chin J, Roberson ED, Wang J, Thwin MT, Bien-Ly N, Yoo J, Ho KO, Yu GQ, Kreitzer A, et al: Aberrant excitatory neuronal activity and compensatory remodeling of inhibitory hippocampal circuits in mouse models of Alzheimer's disease. Neuron 55: 697-711, 2007.

32. Wang X, Wang ZH, Wu YY, Tang H, Tan L, Wang X, Gao XY, Xiong YS, Liu D, Wang JZ and Zhu LQ: Melatonin attenuates scopolamine-induced memory/synaptic disorder by rescuing EPACs/miR-124/Egr1 pathway. Mol Neurobiol 47: 373-381, 2013.

33. Yan BC, Park JH, Chen BH, Cho JH, Kim IH, Ahn JH, Lee JC, Hwang IK, Cho JH, Lee YL, et al: Long-term administration of scopolamine interferes with nerve cell proliferation, differentiation and migration in adult mouse hippocampal dentate gyrus, but it does not induce cell death. Neural Regen Res 9: 1731-1739, 2014.

34. Horisawa $\mathrm{T}$, Ishibashi $\mathrm{T}$, Nishikawa $\mathrm{H}$, Enomoto $\mathrm{T}$, Toma $\mathrm{S}$, Ishiyama $\mathrm{T}$ and Taiji $\mathrm{M}$ : The effects of selective antagonists of serotonin 5-HT7 and 5-HT1A receptors on MK-801-induced impairment of learning and memory in the passive avoidance and Morris water maze tests in rats: Mechanistic implications for the beneficial effects of the novel atypical antipsychotic lurasidone Behav Brain Res 220: 83-90, 2011.

35. Wang Z, Li J, Wang Z, Xue L, Zhang Y, Chen Y, Su J and Li Z: L-tyrosine improves neuroendocrine function in a mouse model of chronic stress. Neural Regen Res 7: 1413-1419, 2012.

36. Candelario-Jalil E, Alvarez D, Merino N and León OS: Delayed treatment with nimesulide reduces measures of oxidative stress following global ischemic brain injury in gerbils. Neurosc Res 47: 245-253, 2003.

37. Lee JC, Kim IH, Cho GS, Park JH, Ahn JH, Yan BC, Kwon HM, $\mathrm{Kim} \mathrm{YM}$, Cheon $\mathrm{SH}$, Cho JH, et al: Ischemic preconditioning-induced neuroprotection against transient cerebral ischemic damage via attenuating ubiquitin aggregation. J Neurol Sci 336: 74-82, 2014.

38. Romanski LM and LeDoux JE: Information cascade from primary auditory cortex to the amygdala: Corticocortical and corticoamygdaloid projections of temporal cortex in the rat Cereb Cortex 3: 515-532, 1993

39. Morris R: Developments of a water-maze procedure for studying spatial learning in the rat. J Neurosci Methods 11 $47-60,1984$.

40. D'Hooge R and De Deyn PP: Applications of the Morris water maze in the study of learning and memory. Brain Res Brain Res Rev 36: 60-90, 2001.

41. Gupta S and Sharma B: Pharmacological benefits of agomelatine and vanillin in experimental model of Huntington's disease. Pharmacol Biochem Behav 122: 122-135, 2014.

42. Blake MG, Boccia MM, Krawczyk MC and Baratti CM: Scopolamine prevents retrograde memory interference between two different learning tasks. Physiol Behav 102: 332-337, 2011.

43. Souza AC, Bruning CA, Acker CI, Neto JS and Nogueira CW: 2-Phenylethynyl-butyltellurium enhances learning and memory impaired by scopolamine in mice. Behav Pharmacol 24: 249-254 2013.

44. Ohno $\mathrm{M}$ and Watanabe $\mathrm{S}$ : Interactive processing between glutamatergic and cholinergic systems involved in inhibitory avoidance learning of rats. Eur J Pharmacol 312: 145-147, 1996.
45. Shi Z, Chen L, Li S, Chen S, Sun X, Sun L, Li Y, Zeng J, He Y and Liu X: Chronic scopolamine-injection-induced cognitive deficit on reward-directed instrumental learning in rat is associated with CREB signaling activity in the cerebral cortex and dorsa hippocampus. Psychopharmacology (Berl) 230: 245-260, 2013.

46. Kim YH and Park JH: Vanillin and 4-hydroxybenzyl alcohol attenuate cognitive impairment and the reduction of cell proliferation and neuroblast differentiation in the dentate gyrus in a mouse model of scopolamine-induced amnesia. Anat Cell Biol 50: 143-151, 2017.

47. Zhao C, Deng W and Gage FH: Mechanisms and functional implications of adult neurogenesis. Cell 132: 645-660, 2008.

48. Jen Y, Manova K and Benezra R: Each member of the Id gene family exhibits a unique expression pattern in mouse gastrulation and neurogenesis. Dev Dyn 208: 92-106, 1997.

49. Jung S, Park RH, Kim S, Jeon YJ, Ham DS, Jung MY, Kim SS, Lee YD, Park CH and Suh-Kim H: Id proteins facilitate self-renewal and proliferation of neural stem cells. Stem Cells Dev 19: 831-841, 2010

50. Lyden D, Young AZ, Zagzag D, Yan W, Gerald W, O'Reilly R, Bader BL, Hynes RO, Zhuang Y, Manova K and Benezra R: Id1 and Id3 are required for neurogenesis, angiogenesis and vascularization of tumour xenografts. Nature 401: 670-677, 1999.

51. Nam HS and Benezra R: High levels of Id1 expression define B1 type adult neural stem cells. Cell Stem Cell 5: 515-526, 2009.

52. Bai G, Sheng N, Xie Z, Bian W, Yokota Y, Benezra R, Kageyama R, Guillemot F and Jing N: Id sustains Hes1 expression to inhibit precocious neurogenesis by releasing negative autoregulation of Hes1. Dev Cell 13: 283-297, 2007.

53. Owens DF and Kriegstein AR: Is there more to GABA than synaptic inhibition? Nat Rev Neurosci 3: 715-727, 2002.

54. Pang KC, Jiao X, Sinha S, Beck KD and Servatius RJ: Damage of GABAergic neurons in the medial septum impairs spatial working memory and extinction of active avoidance: Effects on proactive interference. Hippocampus 21: 835-846, 2011.

55. Roland JJ, Stewart AL, Janke KL, Gielow MR, Kostek JA Savage LM, Servatius RJ and Pang KC: Medial septum-diagonal band of Broca (MSDB) GABAergic regulation of hippocampal acetylcholine efflux is dependent on cognitive demands. J Neurosci 34: 506-514, 2014.

56. Van der Zee EA and Luiten PG: GABAergic neurons of the rat dorsal hippocampus express muscarinic acetylcholine receptors. Brain Res Bull 32: 601-609, 1993.

57. Navarria A, Wohleb ES, Voleti B, Ota KT, Dutheil S, Lepack AE, Dwyer JM, Fuchikami M, Becker A, Drago F and Duman RS Rapid antidepressant actions of scopolamine: Role of medial prefrontal cortex and M1-subtype muscarinic acetylcholine receptors. Neurobiol Dis 82: 254-261, 2015.

58. Voleti B, Navarria A, Liu RJ, Banasr M, Li N, Terwilliger R, Sanacora G, Eid T, Aghajanian G and Duman RS: Scopolamine rapidly increases mammalian target of rapamycin complex 1 signaling, synaptogenesis, and antidepressant behavioral responses. Biol Psychiatry 74: 742-749, 2013.

59. Li G, Bien-Ly N, Andrews-Zwilling Y, Xu Q, Bernardo A, Ring K, Halabisky B, Deng C, Mahley RW and Huang Y GABAergic interneuron dysfunction impairs hippocampal neurogenesis in adult apolipoprotein E4 knockin mice. Cell Stem Cell 5: 634-645, 2009

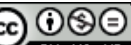

This work is licensed under a Creative Commons Attribution-NonCommercial-NoDerivatives 4.0 International (CC BY-NC-ND 4.0) License. 